\title{
A QUARTA CAPA DE LIVROS DIDÁTICOS DE INGLÊS À LUZ DA TEORIA DE GÊNEROS DISCURSIVOS DA ESCOLA DE SIDNEY
}

\author{
Renato Caixeta SILVA ${ }^{1}$
}

\begin{abstract}
Resumo: Neste trabalho, apresenta-se a análise do gênero quarta capa de livros didáticos de inglês com base nas ideias sobre gênero da Escola de Sidney, considerando-o como parte do contexto cultural escolar e comercial. Apresentam-se, primeiramente, os referenciais teóricos dessa Escola e, nesta linha, a ideia de gênero como uma atividade linguística e social organizada em estágios e voltada a objetivos, que tem uma configuração contextual e elementos com propósitos inerentes. Além disso, é feita uma análise linguístico-discursiva de aspectos ideacionais e interpessoais de dois exemplares do gênero, com base na proposta de Martin e Rose (2003 e 2007), evidenciando que o livro didático de inglês é representado, nesse gênero, como agente importante nos processos de ensino e aprendizagem. Por fim, argumenta-se sobre a implicação deste trabalho para cursos de formação de professores.
\end{abstract}

Palavras-chave: Gênero. Quarta capa. Livro didático de inglês. Escola de Sidney.

\section{Introdução}

Não parecem ser muitos os trabalhos acadêmicos referentes ao gênero discursivo quarta capa. Algumas tentativas de descrevê-lo existem como os trabalhos de Cristóvão (2007) e o de Marchezan e Motta-Roth (2009), ambos lidando com quartas capas de livros não didáticos. O trabalho de Cristóvão não apenas descreve o gênero com base no Interacionismo sociodiscursivo, mas também propõe o uso e a confecção de sequências didáticas para que tal gênero seja incorporado ao grupo de outros gêneros a serem usados em aulas de inglês. Já o trabalho de Marchezan e Motta-Roth (2009) descreve a quarta capa de livros acadêmicos na visão bakhtiniana, enfatizando sua constituição, sua recepção e seu funcionamento como gênero estável. Em suma, esses trabalhos mostram que a quarta capa pode ser entendida como um

\footnotetext{
${ }^{1}$ Professor titular área de Letras (Inglês) no Centro Federal de Educação Tecnológica de Minas Gerais (CEFETMG).E-mail: rencaixe@yahoo.com.br
} 
gênero específico, independente da visão teórica utilizada para se estudá-la, e ainda pode ser instrumento utilizado no ensino.

O presente trabalho tem como objetivo analisar o gênero quarta capa de livros didáticos de inglês à luz da visão sobre gêneros discursivos preconizada pela Escola de Sidney. Dois pontos, então, o diferenciam dos trabalhos mencionados anteriormente: a visão teórica e o gênero em si, sendo que aqui são analisados exemplares de um gênero pertencente às esferas escolar e comercial - quartas capas de livros didáticos de inglês.

Para se alcançar o objetivo proposto, primeiramente será apresentada a teoria de gêneros com os princípios da Linguística Sistêmico-Funcional (HALLIDAY; HASAN, 1989; HALLIDAY, 2007; EGGINS; MARTIN, 1996; MARTIN, 1997; MARTIN; ROSE, 2006; VIAN JR; LIMA-LOPES, 2005). Em seguida, busca-se caracterizar o gênero a ser analisado com base em autores que já tenham feito análise de textos dessa natureza (BHATIA, 2004, por exemplo) embora não necessariamente de livros didáticos de inglês. Também se esquematiza uma possível estrutura do gênero em questão tomando como base as ideias e análises apresentadas por Eggins e Martin (1996), Vian Jr e Lima-Lopes (2005). A análise linguísticodiscursiva de duas quartas capas é baseada nos sistemas discursivos de avaliatividade (do inglês appraisal) e ideação (do inglês ideation), conforme Martin e Rose (2003), também Martin e Rose (2007). Por fim, argumenta-se sobre a importância da conscientização sobre tal gênero por parte de docentes em geral, os quais são responsáveis pela seleção de livros didáticos, no caso, de inglês.

É importante ressaltar alguns pontos que justificam este trabalho e a maneira como é organizado. Em primeiro lugar, textos de quartas capas de livros em geral, e em especial de livros didáticos, apresentam descrição e uma avaliação do material em questão, daí a consideração das ideias referentes à ideação e avaliatividade descritas mais adiante. Além disso, textos exemplares desse gênero podem ser referências para a escolha de materiais de ensino de língua (JOHNSON et al., 2008; SILVA, 2010), e torna-se interessante então que tal gênero seja descrito para uma melhor compreensão a seu respeito. Por fim, é importante frisar que o livro didático de inglês é entendido como um elemento do cotidiano social, com importância pedagógica, política, econômica e cultural (SILVA, 2012). Portanto, este artigo trata não de elementos do livro didático ou metodologias e abordagens veiculadas, mas sobre um dos gêneros que fazem parte de sua composição, já que o livro didático em si pode ser considerado um macrogênero (MARTIN; ROSE, 2006), isto é, um gênero que se constitui de vários outros gêneros, como defendido por Silva (2012). 


\section{A abordagem de gêneros da Escola de Sidney}

Os estudos de gêneros discursivos, atualmente, estão vinculados a várias tradições teóricas, como por exemplo, a Sociorretórica, a Sociossemiótica, o Interacionismo Sociodiscursivo. Embora distintas em seus pressupostos e contextos de surgimento, essas tradições não se excluem e, em vários trabalhos, autores pesquisadores de diferentes tradições podem ser mencionados. Aqui, mais especificamente, será considerada a tradição australiana (Escola de Sidney) de estudos de gêneros, e assume-se, como Johns (2002), que essas tradições têm princípios em comum: a construção social de textos; a determinação, pelo contexto e a comunidade, do propósito e da função do texto; a distinção de valores entre os textos feita pela comunidade; a determinação de convenções de operacionalização dos gêneros e a consequente imposição de restrições; a regulação de conteúdo pela comunidade; a consideração da língua e de elementos linguísticos em conjunto com propósitos retóricos, e daí o entendimento de que as escolhas linguísticas não estão imunes a tais propósitos; e, finalmente, o papel de ideologias na condução de gêneros em contextos educacionais.

De acordo com os adeptos da Linguística Sistêmico-Funcional, a língua é um sistema no qual são feitas escolhas para a produção de significados (NEVES, 2004). O interesse reside no uso da língua em contexto social, e assume-se que, ao usar a língua, o indivíduo produz (ou negocia) significados, influenciado pelas características (ou variáveis) deste contexto mais imediato de uso da língua, ou contexto de registro (HALLIDAY; HASAN, 1989). Acredita-se que o uso das formas linguísticas está condicionado pelo campo do discurso (o conteúdo), pelas relações entre participantes, e pelo modo (canal de comunicação da mensagem) (HASAN, 1989). Da mesma forma que o contexto molda o uso da língua, esta também exerce sua influência naquele, havendo uma relação mútua (MARTIN, 1997).

São consideradas três metafunções da linguagem, que podem ser entendidas como os usos que se faz da linguagem: metafunção ideacional (representar experiências externas e internas do mundo circundante), metafunção interpessoal (estabelecer relações entre os usuários da língua), e a metafunção textual (organizar a mensagem, do ponto de vista linguístico, para com ela agir no mundo).

Para adeptos dessa teoria, há um paralelo entre as metafunções e as variáveis de contexto de registro (MARTIN, 1997), estando a metafunção ideacional voltada para o campo, a metafunção interpessoal ligada às relações, e a metafunção textual relacionada ao modo.

Ainda, para Martin (1997), o contexto social também é estratificado, estando dividido em contexto de registro e contexto de cultura. Neste, mais abrangente e em maior nível de 
abstração, encontra-se o gênero que, por sua vez, é definido como processo social estratificado (em estágios), orientado para objetivos e, através desse processo, os sujeitos (também sociais) organizam suas vidas (MARTIN, 1997). A teoria de gêneros sugere o desdobramento de textos com funções diferentes na cultura, a partir de formas distintas, organizando-se por estágios ou passos (EGGINS; MARTIN, 1996). Trata-se de uma relação probabilística (e não determinista) que prevê alternativas inerentes na relação dialógica entre língua e contexto. Nessa perspectiva, gênero é definido como uma atividade social realizada pela linguagem, organizada em estágios, com orientação a propósitos, em que os usuários de uma língua se engajam como membros de uma cultura de modo a organizarem suas vidas (EGGINS, 1994; MARTIN, 1997).

Para Martin, a correlação direta entre as metafunções da linguagem e as variáveis do contexto de registro mostra que os significados são construídos de maneira que uma modificação num nível afetará todos os outros (VIAN JR; LIMA-LOPES, 2005). Isso significa que "escolhas no nível do contexto de cultura (gênero) refletir-se-ão nas escolhas no nível situacional (registro); tais escolhas, por sua vez, serão materializadas pela linguagem, uma vez que gênero e registro são conceitos abstratos" (VIAN JR; LIMA-LOPES, 2005, p. 35). O registro, então, é o ponto de partida para o estudo de um gênero, pois é ele que traz elementos específicos da situação em que determinado gênero ocorre, a denominada configuração contextual (HASAN, 1989).

Sendo produzidos no contexto de cultura, gêneros discursivos surgem ou se modificam dependendo das atividades sociais ocorridas naquele contexto. Assim, na cultura educacional (HALLIDAY, 2007[1991]), há as atividades de anunciar e apresentar materiais didáticos (no caso aqui, o livro didático de inglês), o que é próprio de quem os produz (autores e editores, principalmente), o que gera os gêneros anúncios de catálogos, quartas capas e apresentações em manuais do professor. Esses textos serão lidos pelos professores, pois conhecer tais materiais é uma de suas atividades na cultura de ensinar.

Assim, pode-se pensar, como Martin e Rose (2006), que a cultura é um sistema de gêneros, pois eles são, em última instância, o que fazemos com a linguagem para atingir determinados objetivos. São as várias atividades humanas que, segundo Bakhtin (2003), à medida que são exercidas pelos seres humanos, esses produzem gêneros que são, muitas vezes, próprios de cada área (cotidiana, publicística, educacional, jornalística, acadêmica, religiosa, dentre outras).

Para se descrever o gênero, então, nessa perspectiva, é necessário pensar na sua configuração contextual, isto é, nas variáveis de campo, relações e modo inerentes ao contexto de realização desse gênero. Por isso, parece pertinente considerar a proposta de análise 
discursiva de Martin e Rose (2003) para se ter noção de significados ideacionais, interpessoais e textuais expressos no gênero quarta capa. Também é preciso considerar, como Hasan (1989) que um gênero possui elementos mais ou menos típicos, e também que nem todos os elementos estarão presentes em todos os exemplares de um gênero, ou numa mesma ordem.

\section{A proposta de análise discursiva de Martin e Rose (2003)}

Martin e Rose (2003) levam em conta essa ideia de gênero e sua proposta de análise do discurso envolve os significados além do nível da sentença, ou seja, a denominada semântica do discurso, e a ideia de que um texto é produzido interativamente na relação entre os interlocutores. Os autores acreditam que as metafunções se entrecruzam no uso da linguagem, e mesmo sendo analisadas separadamente por questões didáticas, ocorrem de maneira conjunta. Martin (1997) ressalta o fato de um recurso discursivo de cunho ideacional, por exemplo, poder estar relacionado, em outro contexto específico, a relações interpessoais. É interessante, então, levar em conta o conceito de topologia, ou seja, questões de proximidade entre os textos analisados e as categorias de análise.

Os sistemas discursivos apresentados pelos autores estão ligados às metafunções e são caracterizados a seguir:

a) avaliatividade (do inglês appraisal): refere-se às atitudes negociadas num texto, sentimentos e valores construídos entre os participantes interlocutores. São significados interpessoais que revelam a natureza interativa do discurso.

b) ideação (do inglês ideation): relaciona-se às atividades executadas, e como são descritas ou classificadas pelos participantes. O foco está no conteúdo, portanto.

c) conjunção (do inglês conjunction): também um tipo ideacional de significação, refere-se às conexões estabelecidas entre as atividades, reformulando, adicionando, sequenciando, explicando. Conexões lógicas do tipo temporal, causal ou outras são formuladas.

d) identificação (do inglês identification): refere-se à introdução dos participantes (pessoas, lugares ou coisas) no discurso e sua manutenção. Trata-se de recursos textuais relacionados à forma como o discurso faz sentido ao receptor.

e) periodicidade (do inglês periodicity): é o fluxo da informação, envolvendo “camadas" de previsão e de consolidação dos significados. São também tipos textuais de significação.

Para cada um desses sistemas, são apresentados recursos de significação que permitem análises de textos em mais de uma perspectiva, às vezes. Para os autores, esses recursos de 
análises textuais (também caracterizados como ferramentas) podem ser usados para vários propósitos. Acredita-se, aqui, que tais recursos podem nortear a análise de textos de divulgação e apresentação de livros didáticos produzidos e veiculados por autores e/ou editores.

Neste trabalho, em especial, apenas as categorias de avaliatividade e ideação são consideradas, as quais parecem servir à análise proposta. São estas as metafunções (interpessoal e ideacional) que representam os aspectos significativos do uso da linguagem: representar (falar sobre) o mundo circundante e agir sobre o interlocutor (NEVES, 2004). Também não são consideradas, aqui, as subcategorias apresentadas pelos autores por questões de espaço e natureza do presente trabalho. Os parágrafos seguintes referem-se aos sistemas de avaliatividade e ideação.

Para Martin e Rose (2003), avaliatividade é um sistema de construção de significados interpessoais, ou seja, as atitudes negociadas num texto, a força dessas atitudes e suas origens. Tais atitudes referem-se à avaliação das coisas (apreciação), ao caráter das pessoas (julgamento) e a sentimentos expressos (afeto). Para os autores, existem recursos na língua para expressar essas atitudes de afeto, julgamento ou apreciação, além de recursos para graduá-las e para atribuí-las a certas fontes / sujeitos engajados no discurso. Dentro da categoria "atitude", usase o termo afeto para se referir à expressão de sentimentos, o termo julgamento para avaliar caráter, e apreciação para se referir ao valor atribuído às coisas. A expressão de atitude, de gradação e engajamento acontece ao mesmo tempo, mas para expressar atitude há três formas, usadas uma de cada vez.

Com relação à ideação, Martin e Rose (2003) dizem que o foco está no conteúdo do discurso e, portanto, descrevem-se as atividades presentes no discurso para mostrar como se classificam e são compostas. Para os autores, não é a realidade pré-existente traduzida em palavras, mas há uma construção da experiência de realidade enquanto discurso e, para tanto, contribuem as orações num texto verbal e os elementos dentro das orações. Os elementos básicos da significação ideacional são os participantes das atividades, os processos, as descrições destes e as circunstâncias em que ocorrem tais processos. Numa análise, o que se procura é estabelecer de quem ou de que se fala, o que é dito a respeito, como é quem ou o que sobre o qual se diz algo, e, por fim, em que circunstâncias ocorre a atividade de que esse alguém ou alguma coisa participa. Os processos, por sua vez, são categorizados em três grandes categorias: fazer, dizer e sentir, e ser. O fazer representa as ações materiais, o dizer e o sentir (considerados juntos) indicam que há uma projeção de outro processo, e o ser focaliza a identificação, a existência, as características, a composição ou a classificação / pertencimento a um grupo. 


\section{O gênero quarta capa de livro didático de inglês: uma possível caracterização}

Para Johns (1997), o livro-texto (que se assemelha e às vezes se iguala ao livro didático de inglês como língua estrangeira), como todo gênero, é motivado por várias forças, sendo uma delas o possível leitor-alvo. A autora assume que os editores direcionam esforços na elaboração de uma capa que seja de fácil apreensão para o aluno (consumidor usuário final), mas na verdade tais esforços têm como meta os professores (profissionais também consumidores). São estes que avaliam os livros, que recorrem a textos de apresentações de livros, recomendam ou não a adoção de um material. Assim, os autores e os editores (mais estes do que aqueles) estabelecem um diálogo mais direcionado ao professor do que ao aluno. O mesmo parece ser válido na consideração de livros didáticos de inglês como língua estrangeira.

O texto da quarta capa de um livro, em geral, é composto por uma menção ao título na forma de manchete, uma descrição ainda que breve do(s) conteúdo(s) e das características da obra em questão, e é impresso como um anúncio encomendado, havendo um endossamento do livro (BHATIA, 2004). Para Bhatia (2004), esse é um gênero com algumas características contextuais, e no entendimento a partir da visão aqui adotada, de modo geral, textos de quarta capas constituem um gênero pois fazem parte das culturas editorial-comercial e escolar, encerrando a atividade de se divulgar livros por esse canal impresso - o próprio livro. Mas, ao considerar quartas capas de livros didáticos de inglês como língua estrangeira, é preciso ter em conta o contexto de registro, mais específico, que determina certos conteúdos a estarem contidos ali, relações interpessoais estabelecidas com professores de inglês, os conhecimentos relacionados à área de ensino de inglês, e comuns aos escritores do texto e seus leitores sobre a área, e o canal que interfere em tudo isso, ou seja, a quarta capa do próprio material. Isso se materializa, em termos linguísticos, nas escolhas lexicais e gramaticais feitas pelos escritores de tais textos.

Entende-se, neste trabalho, que as quartas capas de livros didáticos (de quaisquer áreas) são um gênero dada a importância do livro didático de modo geral na cultura educacional e na cultura comercial (SOUZA, 1996; SILVA, 2012). Dentro deste grupo está a quarta capa do livro didático de inglês como língua estrangeira, que tem um contexto específico envolvendo (i) um determinado campo - o ensino do idioma inglês, as abordagens e metodologias de ensino, outros aspectos relacionados ao ensinar e aprender, como autonomia e afetividade, habilidades e tipos de atividades; (ii) relações estabelecidas com um público alvo objetivando promoção de venda - os professores de língua inglesa que dominam ou compreendem os termos específicos da área, responsáveis pela escolha de um livro idealmente o mais adequado ao seu contexto de 
ensino; e, por fim, (iii) o modo, ou como a mensagem se realiza, pois a quarta capa em si, o papel, é o canal de veiculação desse texto promocional convencionalmente escrito por editores (BHATIA, 2004), ou representantes da firma editorial, ainda que esta firma seja representada pelo próprio autor do livro.

A leitura de duas quartas capas de livros didáticos estrangeiros para ensino de inglês em nível avançado revela alguns pontos em comum, embora organizados em sequências diferentes, em layouts distintos. Podem ser tomados como elementos desse gênero em questão:

- identificação do livro, que pode ser em forma de título ou manchete, ou destacando o título do livro ao longo do texto com fontes em itálico ou negrito ou em outra cor;

- estabelecimento do campo do saber a que o livro didático se refere: no caso das quartas capas em questão, o ensino de inglês para alunos avançados;

- menção e descrição do público-alvo a que o livro em questão se destina (alunos avançados com xx horas de estudo, ou prestes a se preparar para exames);

- descrição breve de conteúdo e/ou metodologia encontrados no livro: menção aos tipos de atividades, ao enfoque e à integração das habilidades;

- menção aos outros elementos do pacote em que esse livro está inserido: resource pack, $\mathrm{CD}$, cassete, teacher's book, workbook, DVD;

- estabelecimento de número de horas previstas para cumprimento do conteúdo;

- nome da editora em destaque;

- credencial ISBN, o que confere legitimação ao livro anunciado.

Em termos linguísticos, espera-se encontrar um texto organizado de maneira concisa, em que imperam caracterizadores de sentido positivo, dado o objetivo de apresentar / divulgar o livro que carrega junto esse "anúncio". Em função do espaço reduzido para o texto (seu tamanho não pode exceder uma página) ressaltam-se as nominalizações ali contidas, o que também se relaciona com a formalidade do texto escrito.

\section{A análise de duas quartas capas de livros didáticos de inglês como língua estrangeira}

Nesta seção, são apresentadas as duas quartas capas consideradas para este trabalho, e procura-se mostrar os elementos do gênero acima mencionados. São os livros Inside Out (Ed. Macmillan) e Advance your English (Ed. Cambridge), ambos direcionados a alunos de nível avançado de inglês, produzidos na Inglaterra, com características distintas. Enquanto o primeiro livro é um volume pertencente a uma coleção de livros / níveis que variam do elementary ao 
advanced; o segundo é um material único, considerado mais conciso, que não prevê como requisito o conteúdo de um material específico.

Percebe-se que, nos dois exemplos utilizados aqui, todos os elementos aludidos podem ser encontrados, às vezes variando a posição na página, a colocação em forma nominalizada ou não, em destaque ou não.

Com base na definição de gênero aqui adotada, são considerados na análise os estágios a que um gênero se divide, orientados para determinados objetivos. Primeiramente, apresentar o material, destacando o seu título (nome e identidade), em seguida, estabelecer o campo do conhecimento e o público-alvo do livro (alunos avançados de inglês como língua estrangeira), depois, descrever abordagem, metodologia, conteúdo, atividades e habilidades a serem encontradas (o que aquele produto oferece e que o aluno consumidor poderá usufruir), mostrar e informar que tal livro tem uma proposta a ser cumprida em $\mathrm{x}$ horas, o que delimita em que contexto de ensino poderá ser adotado pelo professor leitor daquele texto. Verificam-se, também, endossamento do que é dito através de menção a páginas em que se encontram os elementos descritos ou à possibilidade de encontrar ajuda no manual do professor, além do nome da editora, firma responsável pela comercialização (determinando o representante a ser contatado, por exemplo), e do código de ISBN e de barras que legitimam o material. Parece pertinente dizer que esses elementos podem ser os elementos obrigatórios desse gênero, mas apenas uma análise que contemple mais exemplares desse gênero poderá trazer a certeza de tal asserção. Tais elementos podem ser visualizados nas Figuras 1 e 2 a seguir.

As tabelas apresentadas na sequência mostram um detalhamento do texto contido nas quartas capas aqui tomadas em conta, e são baseadas nas ideias sobre avaliatividade (Tabelas 1 e 2) e ideação (Tabelas 3 e 4) de Martin e Rose (2003, 2007). 
Figura 1 - Quarta capa de Inside Out Advanced, Editora Macmillan

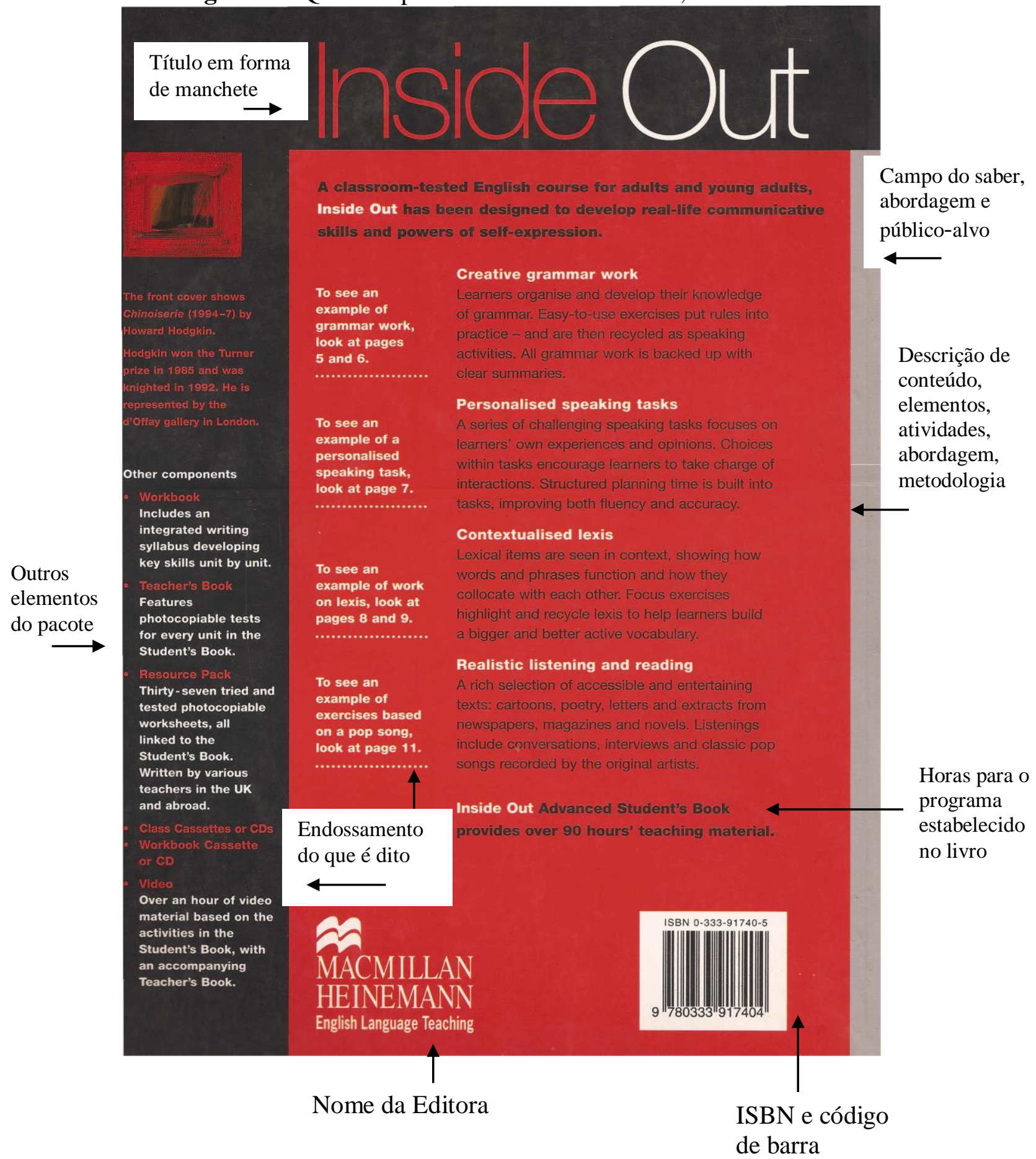


Figura 2 - Quarta capa Advance your English, Editora Cambridge University Press
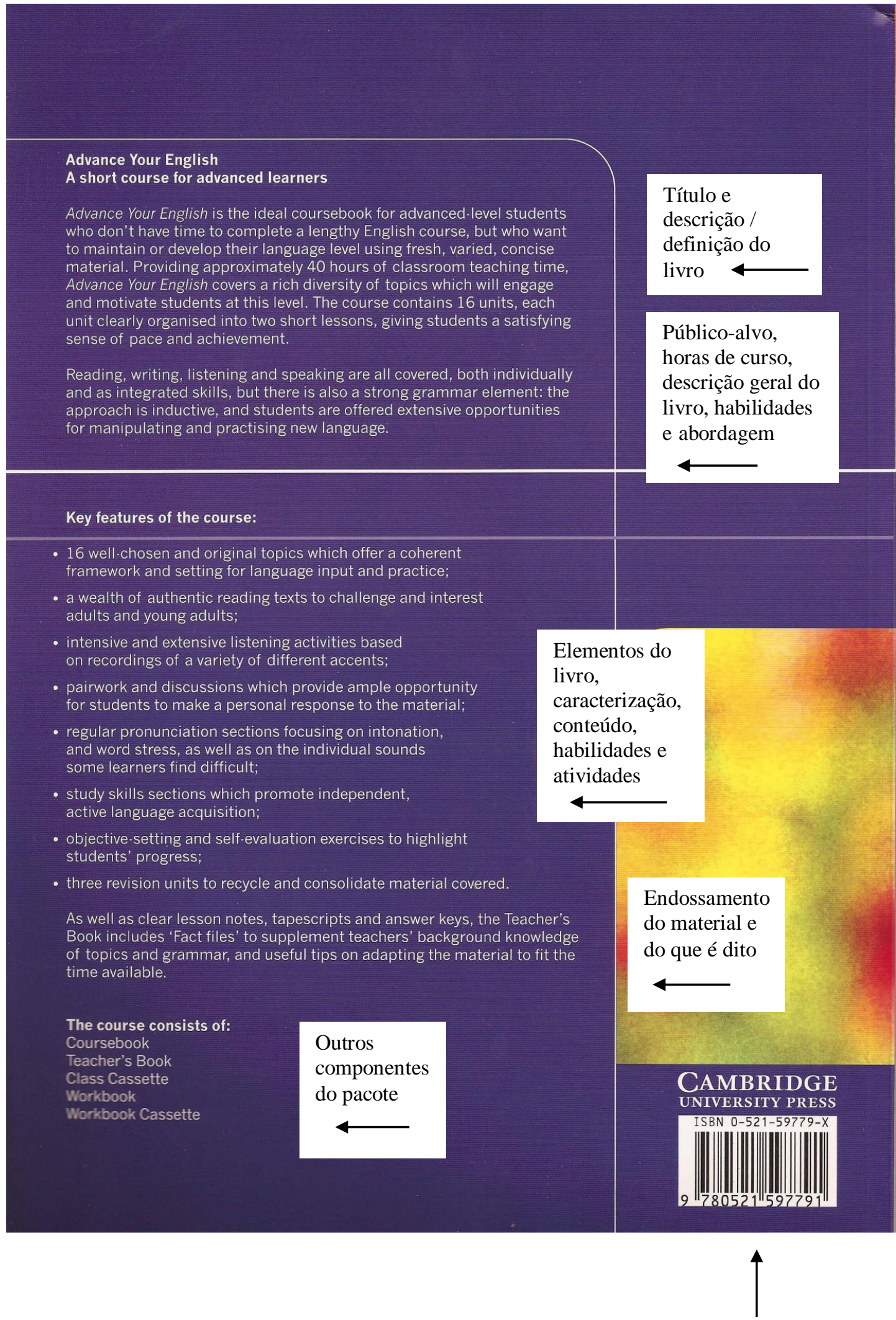

Nome da Editora, ISBN, código de barra 
Tabela 1 - Categorias de avaliatividade observadas na quarta capa de Inside Out Advanced

\begin{tabular}{|c|c|c|c|c|}
\hline \multicolumn{3}{|c|}{ Atitude } & Gradação & Engajamento / Fonte \\
\hline Afeto & Julgamento & Apreciação & & \\
\hline & & $\begin{array}{l}\text { Creative } \\
\text { Grammar work; } \\
\text { Easy-to-use } \\
\text { exercises; } \\
\text { Real-life } \\
\text { communicative } \\
\text { skills; } \\
\text { Clear } \\
\text { summaries; } \\
\text { Challenging } \\
\text { speaking } \\
\text { activities; } \\
\text { Contextualized } \\
\text { lexis; } \\
\text { Bigger and } \\
\text { better active } \\
\text { vocabulary; } \\
\text { Accessible and } \\
\text { entertaining } \\
\text { texts; } \\
\text { Realistic } \\
\text { listening and } \\
\text { reading; } \\
\text { Integrated } \\
\text { writing } \\
\text { syllabus; } \\
\text {... }\end{array}$ & $\begin{array}{l}\text { Rich selection; } \\
\text { Tests for every unit; } \\
\text { (Worksheets) all linked to the } \\
\text { student's book }\end{array}$ & $\begin{array}{l}\text { To see an example of... } \\
\text { Classroom tested ... } \\
\text { by various writers in the UK } \\
\text { and abroad... } \\
\text {...tried and tested... } \\
\text {...video material based on... }\end{array}$ \\
\hline
\end{tabular}

Tabela 2 - Categorias de avaliatividade observadas na quarta capa de Advance your English

\begin{tabular}{|c|c|c|c|c|}
\hline \multicolumn{3}{|l|}{ Atitude } & \multirow[t]{2}{*}{ Amplificação } & \multirow[t]{2}{*}{ Fonte } \\
\hline Afeto & Julgamento & Apreciação & & \\
\hline $\begin{array}{l}\text { Satisfying sense of } \\
\text { pace and } \\
\text { achievement }\end{array}$ & $\begin{array}{l}\text { The ideal coursebook } \\
\text { for students who } \\
\text { don't have time... } \\
\text { who want to } \\
\text { maintain or develop } \\
\text { their language } \\
\text { level... }\end{array}$ & $\begin{array}{l}\text { Short course; } \\
\text { Fresh, varied, } \\
\text { concise material; } \\
\text { Extensive } \\
\text { opportunities; } \\
\text { Individually and } \\
\text { integrated skills; } \\
\text { Original topics; } \\
\text { Coherent } \\
\text { framework; } \\
\text { Authentic texts; } \\
\text { Regular } \\
\text { pronunciation } \\
\text { sections; } \\
\text { Intensive and } \\
\text { extensive listening } \\
\text { activities; } \\
\text { Independent active } \\
\text { language } \\
\text { acquisition; }\end{array}$ & $\begin{array}{l}\text { A rich diversity of } \\
\text { topics } \\
\text { Clearly organized } \\
\text { (each unit) } \\
\text { (Skills) area all } \\
\text { covered... } \\
\text { A strong } \\
\text { grammar } \\
\text { element; } \\
\text { Well-chosen; } \\
\text { A wealth of ample } \\
\text { opportunity ... }\end{array}$ & $\begin{array}{l}\text { Based on } \\
\text { recordings of a } \\
\text { variety of different } \\
\text { accents; } \\
\text { Some teachers find } \\
\text { difficult; }\end{array}$ \\
\hline
\end{tabular}


As Tabelas 1 e 2 mostram que os produtores desses textos apresentam a seus interlocutores, os professores, uma apreciação sempre positiva do livro didático, o que está de acordo com o objetivo do gênero quarta capa de livros didáticos. Isso significa que é estabelecida uma relação com o interlocutor de maneira que ele possa ter credibilidade e confiança no livro didático, evidenciadas também pelas fontes das informações e das apreciações ali veiculadas. As atitudes são confiáveis porque as atividades já foram testadas em sala de aula, o livro ou parte do pacote em que ele está inserido foi escrito por vários autores e, além disso, são considerados diferentes sotaques da língua. A gradação das atitudes também se faz sempre de maneira positiva, enfatizando as apreciações feitas por pessoas que têm o maior interesse no fato de o livro em questão ser adotado, ou seja, seu autor ou editor. Quanto às atitudes, evita-se julgamento ou expressões de afeto. Quando aparecem expressões de afeto (Tabela 2), essas se relacionam ao afeto a ser produzido ou tido pelo aluno, não por parte de quem escreve o texto. Tenta-se evitar, talvez, uma subjetividade, dando mais ênfase àquilo que pode ser visível ao se observar o livro e seus elementos, o que é expresso pelas apreciações.

A seguir, considera-se o aspecto ideacional, apresentando uma análise em nível macro, tendo em mente apenas os participantes e os tipos de processos em que estão envolvidos ao longo do texto. Para melhor visualização dos aspectos ideacionais, seguem duas tabelas:

Tabela 3 - Categorias de ideação observadas na quarta capa do livro Inside Out, Editora Macmillan

\begin{tabular}{|c|c|c|c|c|c|c|c|}
\hline \multirow[t]{3}{*}{ Participante } & \multicolumn{7}{|c|}{ Processo (formas de participação) } \\
\hline & \multirow[t]{2}{*}{ Fazer } & \multirow{2}{*}{$\begin{array}{l}\text { Significar } \\
\text { dizer/sentir }\end{array}$} & \multicolumn{4}{|c|}{ Ser } & \multirow[b]{2}{*}{ Existência } \\
\hline & & & Qualidade & Classe & Partes & Identidade & \\
\hline Inside Out & $\begin{array}{l}\text { Provides } 90 \\
\text { hours' } \\
\text { teaching } \\
\text { material }\end{array}$ & & & & & $\begin{array}{l}\text { Classroom } \\
\text { tested } \\
\text { English } \\
\text { course } \\
\text { designed to } \\
\text { develop... }\end{array}$ & \\
\hline $\begin{array}{l}\text { Grammar } \\
\text { Work }\end{array}$ & & & Creative & & & & \\
\hline Learners & $\begin{array}{l}\text { Organize } \\
\text { and develop } \\
\text { knowledge... }\end{array}$ & & & & & & \\
\hline Exercises & $\begin{array}{l}\text { Put rules } \\
\text { into } \\
\text { practices... }\end{array}$ & & Easy-to-use & & & & \\
\hline Summaries & $\begin{array}{l}\text { Back up } \\
\text { grammar } \\
\text { work }\end{array}$ & & Clear & & & & \\
\hline Choices & $\begin{array}{l}\text { Encourage } \\
\text { learners }\end{array}$ & & & & $\begin{array}{l}\text { Within } \\
\text { tasks }\end{array}$ & & \\
\hline
\end{tabular}




\begin{tabular}{|c|c|c|c|c|c|c|}
\hline Participante & & Processo (fo & mas de par & ticipação) & & \\
\hline $\begin{array}{l}\text { Speaking } \\
\text { tasks }\end{array}$ & $\begin{array}{l}\text { Focus on } \\
\text { learners, } \\
\text { own } \\
\text { experiences } \\
\text { and opinions }\end{array}$ & Challenging & & $\begin{array}{l}\text { A Series of } \\
\text { Structured } \\
\text { planning } \\
\text { time is built } \\
\text { into... }\end{array}$ & Personalized & \\
\hline Learners & $\begin{array}{l}\text { Take charge } \\
\text { of } \\
\text { interactions }\end{array}$ & & & & & \\
\hline Planning time & \begin{tabular}{|l} 
Improve \\
fluency and \\
accuracy
\end{tabular} & & & & & \\
\hline $\begin{array}{l}\text { Lexis / lexical } \\
\text { items }\end{array}$ & $\begin{array}{l}\text { Showing } \\
\text { how words... }\end{array}$ & Contextualized & & $\begin{array}{l}\text { Words and } \\
\text { phrases }\end{array}$ & & \\
\hline $\begin{array}{l}\begin{array}{l}\text { Words } \\
\text { phrases }\end{array} \\
\end{array}$ & $\begin{array}{l}\text { Function } \\
\text { Collocate } \\
\end{array}$ & & & & & \\
\hline $\begin{array}{l}\text { Focus } \\
\text { exercises }\end{array}$ & \begin{tabular}{|l|} 
Highlight \\
and recycle \\
lexis \\
Help \\
learners
\end{tabular} & & & & & \\
\hline Learners & $\begin{array}{l}\text { Build ...voca } \\
\text { bulary }\end{array}$ & & & & & \\
\hline $\begin{array}{l}\text { Vocabulary } \\
\text { (built } \\
\text { learners) }\end{array}$ & & $\begin{array}{l}\text { Bigger } \\
\text { Better active }\end{array}$ & & & & \\
\hline $\begin{array}{l}\text { Reading and } \\
\text { Listening }\end{array}$ & & & & & Realistic & \\
\hline $\begin{array}{l}\text { Selection of } \\
\text { texts }\end{array}$ & & $\begin{array}{l}\text { Rich, } \\
\text { accessible, } \\
\text { entertaining }\end{array}$ & $\begin{array}{l}\text { Cartoons, } \\
\text { poetry, } \\
\text { letters... }\end{array}$ & & & \\
\hline Listenings & & & $\begin{array}{l}\text { Conversat } \\
\text { ions, } \\
\text { interviews } \\
\text {, songs... }\end{array}$ & & $\begin{array}{l}\text { By original } \\
\text { artists }\end{array}$ & \\
\hline Workbook & & & & & & $\begin{array}{l}\text { Includes } \\
\text { integrated } \\
\text { writing } \\
\text { syllabus }\end{array}$ \\
\hline $\begin{array}{l}\text { Teacher's } \\
\text { book }\end{array}$ & & & & & & $\begin{array}{l}\text { Features } \\
\text { photoco- } \\
\text { piable tests }\end{array}$ \\
\hline $\begin{array}{l}\text { Resource } \\
\text { Pack }\end{array}$ & & & & & & $\begin{array}{l}37 \text { tried } \\
\text { and tested } \\
\text { photoco- } \\
\text { piable } \\
\text { worksheets } \\
\text {... } \\
\end{array}$ \\
\hline $\begin{array}{l}\text { Student's } \\
\text { book }\end{array}$ & & & & & $\begin{array}{l}\text { Written by } \\
\text { various } \\
\text { teachers in } \\
\text { the UK and } \\
\text { abroad }\end{array}$ & \\
\hline Video & & & & & $\begin{array}{l}\text { Over an } \\
\text { hour, based } \\
\text { on ... }\end{array}$ & \\
\hline
\end{tabular}


Tabela 4 - Categorias de ideação observadas na quarta capa do livro Advance your English, Cambridge University Press

\begin{tabular}{|c|c|c|c|c|c|c|c|}
\hline \multirow[t]{3}{*}{ Participante } & \multicolumn{7}{|c|}{ Processo (formas de participação) } \\
\hline & \multirow[t]{2}{*}{ Fazer } & \multirow{2}{*}{$\begin{array}{l}\text { Significar } \\
\text { dizer/sentir }\end{array}$} & \multicolumn{5}{|c|}{ Ser } \\
\hline & & & Qualidade & Classe & Partes & $\begin{array}{l}\text { Identi- } \\
\text { dade }\end{array}$ & $\begin{array}{l}\text { Exis- } \\
\text { tência }\end{array}$ \\
\hline $\begin{array}{l}\text { Advance your } \\
\text { English }\end{array}$ & & & & & & $\begin{array}{l}\text { short } \\
\text { course } \\
\text { ideal ... }\end{array}$ & \\
\hline Students & & & & $\begin{array}{l}\text { Advance level } \\
\text { who don't } \\
\text { have time... }\end{array}$ & & & \\
\hline Material & $\begin{array}{l}\text { Provides } 40 h \\
\text { of teaching }\end{array}$ & & $\begin{array}{l}\text { Fresh, varied, } \\
\text { concise }\end{array}$ & & & & \\
\hline Topics & $\begin{array}{l}\text { Engage and } \\
\text { motivate sts }\end{array}$ & & & & & & \\
\hline The course & & & & & 16 units & & \\
\hline Each unit & $\begin{array}{l}\text { Giving sts a } \\
\text { satisfying } \\
\text { sense of pace } \\
\text { and } \\
\text { achievement }\end{array}$ & & $\begin{array}{l}\text { Clearly } \\
\text { organized }\end{array}$ & & $\begin{array}{l}\text { Two } \\
\text { short } \\
\text { lessons }\end{array}$ & & \\
\hline $\begin{array}{l}\text { Skills (reading, } \\
\text { writing, } \\
\text { listening and } \\
\text { speaking) }\end{array}$ & & & $\begin{array}{l}\text { Integrated } \\
\text { Individualized }\end{array}$ & & & & \\
\hline (The book) & $\begin{array}{l}\text { Covers } \text { (the } \\
4 \text { skills) }\end{array}$ & & & & & & \\
\hline $\begin{array}{l}\text { Grammar } \\
\text { element }\end{array}$ & & & Strong & & & & There is \\
\hline The approach & & & & & & $\begin{array}{l}\text { Inductiv } \\
e\end{array}$ & \\
\hline The book & $\begin{array}{l}\text { "offers } \\
\text { students } \\
\text { opportunities } \\
\text {.." }\end{array}$ & & & & & & \\
\hline Students & Can practice & & & & & & \\
\hline Features & & & & & & $\begin{array}{l}16 \\
\text { topics }\end{array}$ & \\
\hline Topics & $\begin{array}{l}\text { Offer } \\
\text { coherent } \\
\text { framework... }\end{array}$ & & Wealth & & & & \\
\hline Reading texts & $\begin{array}{l}\text { Challenge } \\
\text { and interest }\end{array}$ & & & & & $\begin{array}{l}\text { Authenti } \\
\text { c }\end{array}$ & \\
\hline $\begin{array}{l}\text { Adults / Young } \\
\text { adults }\end{array}$ & $\begin{array}{l}\text { Are } \\
\text { challenged }\end{array}$ & & & & & & \\
\hline $\begin{array}{l}\text { Listening } \\
\text { activities }\end{array}$ & & & & & & $\begin{array}{l}\text { Intensiv } \\
e \quad \text { and } \\
\text { extensiv } \\
e\end{array}$ & \\
\hline
\end{tabular}

Percebe-se, nas Tabelas 3 e 4, que o livro didático é caracterizado pelo fato de ser algo (um curso, um livro escrito por pessoas renomadas) ou de alguma forma (realista, com tópicos autênticos, variado ou conciso). Ressaltam-se suas características como o pertencimento a um 
grupo (de livros avançados), seus elementos / partes são identificados de maneira a dar-lhes uma caracterização específica ou única (os textos para leituras são autênticos, a abordagem é indutiva, o livro do aluno é escrito por diferentes autores, as atividades de fala são personalizadas). Ressaltam-se as qualidades do material ou de seus elementos (os tópicos são ricos, o elemento gramatical é forte e presente no livro, as atividades e as habilidades enfocadas são integradas). No que se refere ao processo de fazer, observa-se que no texto do livro Inside Out tanto o livro, ou seus elementos, quanto os seus usuários fazem algo (os exercícios colocam as regras de maneira clara, os alunos escolhem / participam ativamente da aprendizagem, constroem vocabulário). Já no texto do livro Advance your English, o participante que atua é muito mais o livro, ou seus elementos, do que o aluno usuário (são os textos para leitura que desafiam e promovem interesse, são os tópicos que oferecem uma estrutura coerente, é o livro que dá a oportunidade de aprendizagem ao aluno, e não o professor, ou o próprio aluno que cria tais oportunidades). Isso mostra que o livro didático é representado ao leitor alvo como um agente ativo no processo de ensino e de aprendizagem (SILVA, 2012), que é ele, o livro, o responsável pelo que pode acontecer no ensino e na aprendizagem. Os alunos (usuários consumidores finais do livro) podem praticar e sofrem a ação de serem desafiados (pelo livro e / ou seus elementos) no processo de aprendizagem. Não parece que, nos textos em questão, ao professor seja dada importância nessa aprendizagem, seja para facilitá-la, seja para guiá-la.

\section{Conclusão}

Este trabalho mostra que é possível uma caracterização da quarta capa de livros didáticos de inglês como língua estrangeira à luz das ideias de gêneros preconizadas pelos adeptos da Linguística Sistêmico-Funcional ou Escola de Sidney, e de elementos da análise discursiva proposta por Martin e Rose (2003). Considerando o livro didático em si como um elemento do cotidiano social, importante em termos políticos, econômicos, culturais e pedagógicos (SILVA, 2012), é possível entender os textos de quartas capas como pertencentes ao contexto de cultura comercial e, ao mesmo tempo, pedagógico, pois neles se descreve o livro em termos de seus aspectos pedagógicos positivos, mas essa descrição tem como objetivo final convencer o professor leitor de que tal livro, com determinadas qualidades, é possível de ser adquirido pelos alunos, os usuários finais.

Mais ainda, observa-se que há recorrência de elementos e características em dois exemplares retirados de livros diferentes, editados por companhias distintas, e produzidos com objetivos não comuns. A recorrência permite caracterizar um gênero, e ainda os objetivos 
comuns que perpassam a produção de textos exemplares desse gênero. Isso significa dizer que, na sociedade, ou na cultura de ensino de línguas, esses textos terão certa importância para determinado público-alvo, satisfazendo certos objetivos das pessoas que os produzem e daquelas que os leem.

Uma implicação deste trabalho pode ser a inclusão, em cursos de formação docente inicial ou continuada, da leitura e análise de quartas capas ao se mencionar a avaliação de obras didáticas. Defende-se ser necessário mostrar ao docente ou futuro docente como esses textos se organizam e que o que é neles veiculado pode tornar esse profissional mais consciente do uso da língua e do que é dito sobre o livro, como é dito, e com que objetivo, enfim, informações importantes para as decisões e análises de livros destinados ao ensino de inglês.

Neste trabalho, por questões de espaço, não foram levados em conta aspectos de significação textual na análise dos textos que servem de exemplo. Entretanto, não se deixa de reconhecer a existência e a importância de tal análise, principalmente sendo a quarta capa um gênero multimodal. A análise textual, então, deveria levar em conta os elementos de composição de um texto dessa natureza, e pode ser assunto de novo artigo sobre quartas capas de livros didáticos de inglês de língua estrangeira.

SILVA, Renato Caixeta. The outside back cover blurb of English coursebooks under the view of the genre theory of Sydney school. Revista do GEL, v. 13, n. 1, p. 157-175, 2016.

Abstract: This paper aims to analyse back cover blurbs of English coursebook as a genre in the light of the ideas proposed by Sydney School, considering it as part of educational, commercial, and cultural contexts. Firstly, the theoretical presuppositions proposed by the School are presented: these presuppositions include the idea that considers the genre as a linguistic and social activity organised in stages and directed to goals, which presents a contextual configuration and elements with inherent goals. In addition, two examples of the genre are analysed under the ideas of the linguistic and discursive proposal according to Martin and Rose (2003, 2007), which make clear the representation of the coursebook as an important agent in teaching and learning processes. At last, it is argued in favour of the implications of this paper for teachers' training courses.

Keywords: Genre. Outside Back Cover Blurb. English Coursebook. Sydney School. 


\section{Referências}

BHATIA, V. J. Integrating research methods. In.: BHATIA, V. Worlds of written discourse: a genre based view. London, Continuum, 2004. p. 155-181.

CRISTÓVÃO, V. L. L. O gênero quarta capa no ensino de inglês. In.: DIONÍSIO, A. P.; MACHADO, A. R.; BEZERRA, M. A. Gêneros Textuais e Ensino. 5. ed. Rio de Janeiro: Editora Lucerna, 2007. p. 95-106.

EGGINS, S.; MARTIN, J. Genres and Registers of Discourse. In.: VAN DIJK, T. A. (Ed.). Discourse: a multidisciplinary introduction. London: Sage, 1996.

HALLIDAY, M. A. K. The notion of "context" in Language Education. In.: WEBSTER, J. J. (Ed.). Language and Education - Collected Works of M. A. K. Halliday, v. 9. London, New York: Continuum, 2007 [1991]. p. 269-290. Contexts of English. In.: WEBSTER, J. J. (Ed.). Language and Education Collected Works of M. A. K. Halliday, v. 9. London, New York: Continuum, 2007 [1994]. p. 306-325.

HASAN, R. The structure of a text. In.: HALLIDAY, M. A. K.; HASAN, R. Language, context and text: aspects of language in social semiotic perspective. Oxford: Oxford University Press, 1989. p. 52-59.

HALLIDAY, M. A. K.; HASAN, R. Language, context and text: aspects of language in social semiotic perspective. Oxford: Oxford University Press, 1989.

JOHNS, A. Introduction: Genres in the Classroom, In.: JOHNS, A. (Ed). Genre in the classroom: multiple perspectives. Mahwah, NJ: Lawrence Eribaum, 2002. p. 3-13.

Pedagogical Genres. In.: JOHNS, A. Text, role and context: developing academic literacies. Cambridge: Cambridge University Press, 1997. p. 46-50.

JOHNSON, K.; KIM, M.; YA-FANG, L.; NAVA, A.; PERKINS, D.; SMITH, A. M.; SOLER-CANELA, O.; LU, W. A step forward: investigating expertise in materials evaluation. In.: ELT - Journal, v. 62/2, Oxford University Press, April, 2008. p. 157-163.

MARQUEZAN, M.; MOTTA-ROTH, D. O gênero contracapa na perspectiva teórica bakhtiniana. Interletras, v. 2, n. 10. Dourados - MS: UNIGRAN, julho a dezembro de 2009.

MARTIN, J. R. Analysing genre: functional parameters. In.: CHRISTIE; F.; MARTIN, J. R. (Ed.). Genre and Institutions: social processes in the workplace and school. London: Cassell. 1997. p. 3-39.

MARTIN, J. R.; ROSE, D. Working with Discourse: meaning beyond the clause. London and New York: Continuum, 2003. $24 / 2 / 2006$

Genre Relations: Mapping Cultures. London, Oakville: Equinox, $1^{\text {st }}$ galley, 
Working with Discourse: meaning beyond the clause. 2. ed. London and New York: Continuum, 2007.

NEVES, M. H. M. A Gramática Funcional. São Paulo: Martins Fontes, 2004.

SILVA, R. C. Representações do livro didático de inglês: análise dos discursos de produtores e usuários com base na Linguística Sistêmico-Funcional. 2012. 318 f. Tese (Doutorado em Letras) - Departamento de Letras, Pontifícia Universidade Católica do Rio de Janeiro, Rio de Janeiro, 2012.

Avaliação e seleção de livros / materiais didáticos para o ensino de línguas - relato de uma oficina. In. Anais do II SILID / I SIMAR. Rio de Janeiro: Edições Entrelugar, 2010, p. 53-63. Disponível em: <http://pt.scribd.com/doc/35152549/Textos-Selecionados-do-IISILID-e-I-SIMAR\#scribd>. Acesso em: 28 mai. 2015.

SOUZA, D. M. Autoridade, autoria e o livro didático. Contexturas 3 - ensino crítico de língua inglesa. São Paulo: APLIESP, 1996. p. 55-60.

VIAN JR., O.; LIMA-LOPES, R. E. A perspectiva teleológica de Martin para a análise de gêneros textuais. In.: MEURER, J. L.; BONINI, A.; MOTTA-ROTH, D. (Org.). Gêneros teorias, métodos, debates. São Paulo: Parábola Editorial, 2005. p. 29-45.

Livros didáticos:

BROADHEAD, A. Advance your English - a short course for advanced learners.

Cambridge: Cambridge University Press, 2002, fifth impression.

JONES, C.; BASTOW, T.; HIRD, J. Inside Out Advanced Student's Book. Oxford:

Macmillan Heinemann, 2001.

Submetido em 29/05/2015

Aceito em 11/01/2016 